\title{
Movement Patterns of Metallic Particles in a Single Phase Compressed Gas Insulated Busduct with Electromagnetic Field Effect
}

\author{
K. B. Madhu Sahu, B. Srinivasa Rao, and J. Amarnath
}

\begin{abstract}
Electrical insulation performance of compressed gas insulated Substation is adversely affected by metallic particle contaminants. Free conducting particles, depending upon their shape, size and location, may lead to serious deterioration of the dielectric strength of the system. The work Presented in this paper analyses the movement pattern of metallic particles in Gas Insulated Busduct (GIB) in the presence of Electromagnetic field. In order to determine the particle trajectories in a GIB, an inner diameter of $55 \mathrm{~mm}$ and outer enclosure diameter of $152 \mathrm{~mm}$ were considered. The movement pattern of metallic particles at different voltages of Aluminum, Copper and Silver in a GIB has been simulated with and without enclosure coating. Typical results shown that there is a considerable increase in movement of the particle when electromagnetic field effect on the particle is considered. This particle movement is greatly reduced while considering dielectric coating inside the surface of the enclosure.
\end{abstract}

Index Terms-Metallic particles, electromagnetic field effect, gas insulated busduct, gas insulated substation.

\section{INTRODUCTION}

During the last three decades, the development of Gas Insulated Switchgear equipment has progressed rapidly worldwide because of the excellent insulation properties of Sulphur hexafluoride $\left(\mathrm{SF}_{6}\right)$ gas [1]. Sulphur-hexafluoride $\left(\mathrm{SF}_{6}\right)$, at a pressure of a few atmospheres, is the preferred as insulating gas. The following are the major advantages of $\mathrm{SF}_{6}$ gas:

1) High dielectric strength

2) Unique arc quenching ability

3) Good thermal stability and conductivity.

It is known, however, that electrical insulation performance of GIS system is adversely affected by metallic particle contaminants [2] The conducting particles can either be free to move in the GIB or they may stick to an energized electrode or to an enclosure surface

A study of CIGRE group suggests that $20 \%$ of failure in GIS is due to the existence of various metallic contaminations in the form of loose particles. Under the influence of high voltage, they can acquire sufficient charge and randomly move in the gap due to the variable electric field. Several authors have reported the movement of particles with reference to a few parameters [3].

Manuscript received February 28, 2013; revised August 5, 2013.

Tauthors are with Electrical and Electronics Engineering, Aditya Institute of Technology and Management, Tekkali, A.P.India (e-mail:kbmadhusahu@gmail.com; saisaketh@rediffmail.com; amarnathjinka@yahoo.com)
It is well known that free conducting particles drastically reduce the dielectric strength of GIS systems. In practical systems it is very difficult to avoid metallic particle contamination. The most likely causes for such contamination are mechanical abrasion, movement of conductors under load cycling and vibrations during shipment. Such particles are

drastically reducing the breakdown voltages as a result of their movement in the electric field.

The presence of contamination can therefore be a problem with gas insulated substations operating at high fields. If the effects of these particles could be eliminated, then this would improve the reliability of compressed gas operating at higher fields to affect a potential reduction in the GIS size with subsequent savings in the cost of manufacture and installation.

Conductors in a GIS/GITL system may be coated with a dielectric material to restore some of the dielectric strength of the compressed gas, which is lost due to surface roughness and contamination by conducting particles. The improvement in the dielectric strength of the system due to coating can be attributed to several effects. Coating reduces the degree of surface roughness on conductors. Also, the high resistance of the coating impedes the development of pre discharges in the gas, thus increasing the breakdown voltage [4]. With coated conductors the particle will acquire a drastically reduced charge, thus the risk of breakdown initiated by a discharge is reduced significantly. Coating thickness has been varied from a few microns to several millimeters and the influence of coated electrodes on the insulation performance has been studied under ac voltages [5].

When the electric field surrounding a particle is increased, an uncharged insulated substations. It would also offer the possibility of metallic particle resting on the surface of support insulator, enclosure or a bare electrode will gradually acquire charge in proportion to the transient voltage. The charge $\mathrm{Q}$ accumulated on the particle is a function of the local electric field $\mathrm{E}$, the shape, orientation, and size of the particle [6]. When the electrostatic force QE on the particle exceeds the gravitational force, the particle lifts up. A further increase in the applied voltage will make the charged particle move into the inter-electrode gap. This increases the problem of flashover. A conducting particle can short-circuit a part of the insulation distance, and thereby initiate a breakdown [7],[ 8].

The work reported in this paper analyses the movement of metallic particle inside a single phase GIB. The simulation considers the particle movement in single-phase GIB with electromagnetic field effect under uncoated and coated 
enclosure. It is observed that the movement of particles for a given voltage level is greatly reduced while considering dielectric coating inside the surface of the enclosure.

\section{Modeling of Gas Insulated Busduct}

A typical horizontal busduct comprising of inner conductor and outer enclosure, filled with $\mathrm{SF}_{6}$ gas is considered for the study as shown in Fig.1. A particle is assumed to be at rest at the enclosure surface, until a voltage sufficient enough to lift the particle and move in the field is applied, After acquiring an appropriate charge in the field, the particle lifts from the enclosure surface and move in the direction of field. If the electrostatic force on the particle over comes the gravitational and frictional force on it, the particle lift-off from the rest position .During return flight, a new charge on the particle is assigned based on the instantaneous electric field.

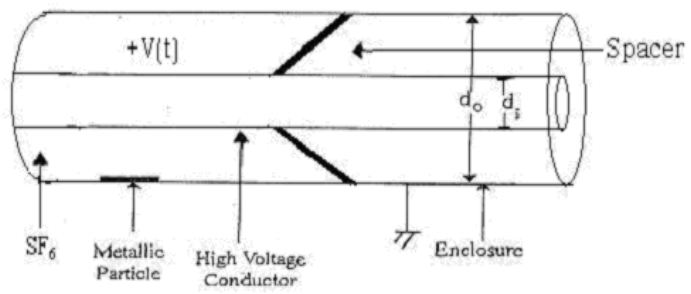

Fig. 1. A typical single phase Gas insulated busduct.

While arriving at a mathematical model of the movement of particles inside a busduct, various properties of gas particle as well as electrical properties of the system has been taken into account. Understanding the dynamics of a metallic particle in a coaxial electrode system is of vital importance for determining the effect of metallic contamination in a gas insulated substations (GIS). The dynamic equation comprises the gravitational force on the particle, charge acquired by the particle, field intensity at the particle location, drag force, gas pressure, restitution co-efficient and the Reynold's number.

The lift-off field for a particle on the surface of an electrode can be estimated by solving the following equations. The gravitational force acting on a particle of mass ' $\mathrm{m}$ ' is given by

$$
F_{g}=\mathrm{mg}
$$

The expression of the electrostatic force is given as

$$
F_{e}=K Q E
$$

where, $K$ is the correction factor less than unity

$Q$ is the particle charge

$E$ is the ambient electric field.

$E(t)$ in a co-axial electrode system can be expressed as

$$
E(t)=\frac{\hat{\mathrm{V}} \operatorname{Sin} \omega \mathrm{t}}{\left[r_{0}-y(t)\right] l_{n}\left[\frac{r_{0}}{r_{i}}\right]}
$$

where, V Sinwt is the supply voltage on the inner electrode,

$r_{o}$ is the enclosure radius, $r_{i}$ is the inner conductor radius

$y(t)$ is the position of the particle which is moving upwards, the distance from the surface of the enclosure towards the inner electrode.

The equation of motion for a particle can be expressed as $[5]$.

$$
m \frac{d^{2} y}{d t^{2}}=F_{e}-m g-F_{d}
$$

where $\quad m=$ mass of the particle.

$y=$ displacement in vertical direction

$F_{e}=$ electrostatic force

$F_{d}=$ drag force

The motion equation using all forces can therefore be expressed as [5-6] becomes

$$
\begin{gathered}
m \ddot{y}(t)=\left[\frac{\Pi \varepsilon_{0} l^{2} E\left(t_{0}\right)}{\ln \left(\frac{2 l}{r}\right)-1} \times V \times 29248 \times 10^{3}\right]\left(\frac{1}{76-x}\right) \sin \omega t \\
-m g-y(t) \Pi r\left[6 \mu K_{d}(\dot{y})+2.656\left[\mu \rho_{g} l \dot{y}\right]^{0.5}\right]
\end{gathered}
$$

\section{Modeling of Single Phase IsOlated Gib With ELECTROMAGNETIC FIELD EFFECT}

Consider an electric field at a point where electric field intensity is $\bar{E}$, the force acting on unit positive charge is $\bar{F}$ $\mathrm{N} / \mathrm{C}$ (or) $\mathrm{V} / \mathrm{m}$. If a charge ' $\mathrm{Q}$ ' coulombs experiences a force is

$$
\bar{F}=Q \bar{E} \text { Newton }
$$

Force on a moving charge $\mathrm{Q}$ with a velocity $\mathrm{V}$ in a magnetic field $B$ is

$$
\bar{F}=Q(\bar{V} \times \bar{B}) \text { Newton }
$$

If charge moves in a region, where the electric field and magnetic fields are simultaneously present, therefore

$$
\bar{F}=Q \bar{E}+Q(\bar{V} \times \bar{B})
$$

$$
\text { or } \begin{gathered}
\bar{F}=Q(\bar{E}+(\bar{V} \times \bar{B})) \text { Newton } \\
\bar{B}=\frac{\mu_{0} \mu_{r} I}{2 \pi \rho} \hat{a}_{\phi}
\end{gathered}
$$

The Lorentz force, $\bar{F}_{L F}=Q \bar{E}+Q(\bar{V} \times \bar{B})$

$$
\bar{F}_{L F}=\frac{\pi \varepsilon_{0} l^{2} E\left(t_{0}\right)}{\ln \left(\frac{2 l}{\gamma}\right)-1} \times\left[\frac{V_{m} \sin \omega t}{\left[\gamma_{0}-y(t)\right] \ln \left(\frac{\gamma_{0}}{\gamma_{1}}\right)}+\dot{y} \frac{\mu I}{2 \pi \rho} \hat{a}_{\phi}\right]
$$


Substitute the above Lorentz Force in the equation (4). Therefore,

$$
\begin{aligned}
& m \frac{d^{2} y}{d t^{2}}=\frac{\pi \varepsilon_{0} l^{2} E\left(t_{0}\right)}{\ln \left(\frac{2 l}{\gamma}\right)-1} \times\left[\frac{V_{m} \sin \omega t}{\left[\gamma_{0}-y(t)\right] \ln \left(\frac{\gamma_{0}}{\gamma_{1}}\right)}+\dot{y} \frac{\mu I}{2 \pi \rho} \hat{a}_{\phi}\right] \\
& -\dot{y} \pi r\left[6 \mu k_{d}(\dot{y})+2.656\left(\mu \rho_{g} l\right)^{0.5}(\dot{y})^{0.5}\right]-m g \operatorname{Sin} \theta
\end{aligned}
$$

\section{Conduction Through a Dielectric CoAting}

In the case of GIS, by using a coating with a light shade on the inside of the enclosure, it is easier to detect impurities such as metallic particles or pieces of dielectric material in the system. Charging of metallic particles in contact with a coated electrode is mainly based on two deferent charge mechanisms.

1) Conduction through a dielectric coating.

2) Micro discharges between the particle and the Coating

Circuit model of charge mechanism of a metallic particle on dielectric coating as shown in Fig. 2.

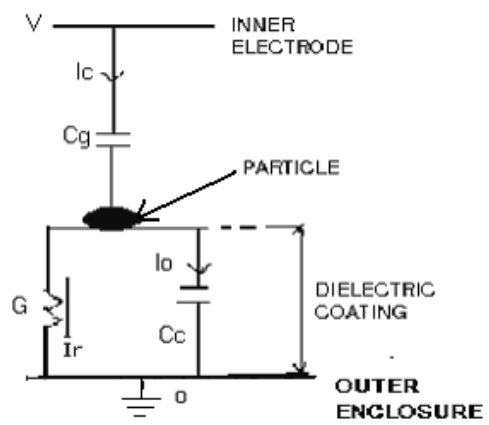

Fig. 2. Circuit model of particle charging through the dielectric coating.

$C_{g}$ represents capacitance between the conductor and the particle whereas $C c$ represents capacitance between the particle and the enclosure. The conductance $G$ represents the part of the dielectric coating where the Charging current is flowing.

The capacitance $C_{o}$ and conductance $G$ in Fig. 3 are both dependent on the dielectric material and thickness, while the capacitance in the gas gap, $C_{g}$ only depends on the gap dimensions.

The solution of the above equation for the electric field near the surface of the enclosure yields electric lift-off field $\left(\mathrm{E}_{\mathrm{L}} \mathrm{O}\right)$

$$
\begin{aligned}
& \left.\mathbf{E}_{\mathbf{L O}}=\left[\frac{m g}{\frac{R}{\omega} B(\phi) r_{\mathrm{in}} \ln \frac{r_{\mathrm{in}}}{r_{\mathrm{t}}}}\right]^{0.5}\left[R\left[1+\frac{C_{\mathrm{c}}}{C_{\mathrm{g}}}\right]^{2}+\frac{1}{R^{2} \omega^{2} C_{\mathrm{g}}^{2}}\right]^{0.5}\right]^{0.5} \\
& =K\left[\left(1+\frac{C_{C}}{C_{g}}\right)^{2}+\frac{1}{R^{2} \omega^{2} C_{g}^{2}}\right]^{0.25}\left(\frac{\rho_{c} T}{S}\right)^{0.5}
\end{aligned}
$$

where, $K$ is a constant. It can be noted that $\mathrm{E}_{\mathrm{LO}}$ is approximately proportional to square root of the thickness and resistivity of the dielectric.

The Lorentz Force equation is given by

$$
\bar{F}_{L F}=\frac{\pi \varepsilon_{0} l^{2} E\left(t_{0}\right)}{\ln \left(\frac{2 l}{\gamma}\right)-1} \times\left[\frac{V_{m} \sin \omega t}{\left[\gamma_{0}-y(t)\right] \ln \left(\frac{\gamma_{0}}{\gamma_{1}}\right)}+\dot{y} \frac{\mu I}{2 \pi \rho} \hat{a}_{\phi}\right]
$$

Substitute the above Lorentz Force in the equation(4) and is given by

$$
\begin{gathered}
m \frac{d^{2} y}{d t^{2}}=\frac{\pi \varepsilon_{0} l^{2} E\left(t_{0}\right)}{\ln \left(\frac{2 l}{\gamma}\right)-1} \times\left[\frac{V_{m} \sin \omega t}{\left[\gamma_{0}-y(t)\right] \ln \left(\frac{\gamma_{0}}{\gamma_{1}}\right)}+\dot{y} \frac{\mu I}{2 \pi \rho} \hat{a}_{\phi}\right] \\
-\dot{y} \pi r\left[6 \mu k_{d}(\dot{y})+2.656\left(\mu \rho_{g} l\right)^{0.5}(\dot{y})^{0.5}\right]-m g \operatorname{Sin} \theta
\end{gathered}
$$

Hence the above equations (10) \& (13) are $2^{\text {nd }}$ order nonlinear differential equation, it can be solved by using Runge-Kutta $4^{\text {th }}$ order method. The simulation results have been presented and analyzed

\section{RESUlTS AND DISCUSSIONS}

Table I shows the radial movement of the particle in a 1-phase isolated Gas Insulated Bus duct of Aluminum, Copper, and silver particles by considering with and without dielectric coating in the presence of Electromagnetic field on the particles are shown in Fig. 3 to Fig. 14 for applied voltages of $75 \mathrm{kV}, 145 \mathrm{kV}$ and $200 \mathrm{kV}$ respectively. The particle is taken as $12 \mathrm{~mm}$ in length with $0.2 \mathrm{~mm}$ radius. Initially the particle is supposed to be resting at the bottom of the enclosure and positioned vertically.

It is observed in the Fig. 3 that the maximum movement of the Aluminum particle is $24.2654 \mathrm{~mm}$ under uncoated enclosure in the presence of electromagnetic field effect on the particle. It is drastically reduced to $0.404 \mathrm{~mm}$ while considering dielectric coating at a given voltage of $75 \mathrm{kV}$ as shown in Fig. 4. The simulated results of maximum movement of particles are shown in Table I.

The movement of copper particle is also given in Table I. It has been observed that the maximum movement of Copper and silver particles are far less than the Aluminum particle even of same size and applied voltage. This is due to the higher density of Copper and silver particles. It is also noticed that as the voltage increases, the maximum movement of Aluminum, copper and silver particles increases significantly.

Fig. 5 and Fig. 6 shows that the maximum movement of the Copper particle is greatly reduced in case of considering dielectric coating in the presence of Electromagnetic field effect on the particle at a given voltage of $75 \mathrm{kV}$.

Similarly Fig. 7 and Fig. 8 also shows that the maximum movement of the Silver particle is greatly reduced in case of considering dielectric coating on the enclosure in the presence of Electromagnetic field effect on the particle at a given voltage of $75 \mathrm{kV}$.

The movement of Aluminum, Copper and Silver particles by considering with and without dielectric coating on the 
enclosure in the presence of Electromagnetic field effect on the particles for the voltages of $145 \mathrm{kV}$ and $200 \mathrm{kV}$ respectively are shown in Fig.9 to Fig. 14. It has been observed that the radial movement of the particle is drastically reduced while considering dielectric coating inside surface of the enclosure.

TABLE I: RADIAL MOVEMENT OF ALUMINUM, COPPER, AND SILVER PARTICLES WITH AND WITHOUT ELECTROMAGNETIC FIELD EFFECT.

\begin{tabular}{|c|c|c|c|}
\hline \multirow{2}{*}{$\begin{array}{c}\text { Voltage } \\
(\mathrm{kV})\end{array}$} & \multirow{2}{*}{ Type } & \multicolumn{2}{|c|}{ Maximum Radial Movement (mm) } \\
\cline { 3 - 4 } & & Uncoated & Coated \\
\cline { 3 - 4 } $75 \mathrm{kV}$ & $\mathrm{Al}$ & 24.2654 & 0.401 \\
& $\mathrm{Cu}$ & 6.0912 & 0.016 \\
& $\mathrm{Ag}$ & 3.9657 & 0.011 \\
\hline \multirow{3}{*}{$145 \mathrm{kV}$} & $\mathrm{Al}$ & $\mathrm{NA}$ & 1.758 \\
& $\mathrm{Cu}$ & 19.9737 & 0.484 \\
& $\mathrm{Ag}$ & 17.7878 & 0.373 \\
\hline \multirow{3}{*}{$200 \mathrm{kV}$} & $\mathrm{Al}$ & NA & 2.950 \\
& $\mathrm{Cu}$ & 28.7404 & 1.050 \\
& $\mathrm{Ag}$ & 26.5696 & 0.876 \\
\hline
\end{tabular}

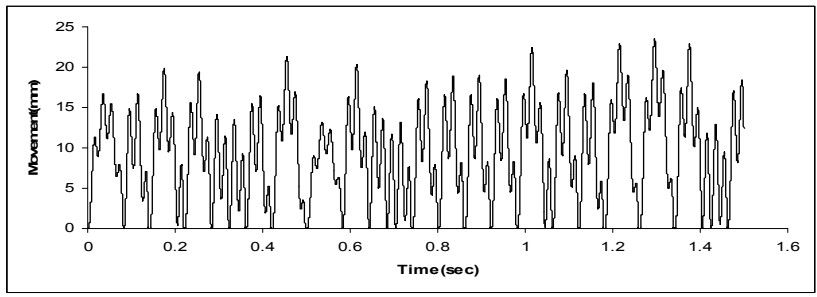

Fig. 3. Movement pattern for Power frequency for $75 \mathrm{kV} / \mathrm{Al} / 12 \mathrm{~mm} / 0.2 \mathrm{~mm}$ radius uncoated enclosure.

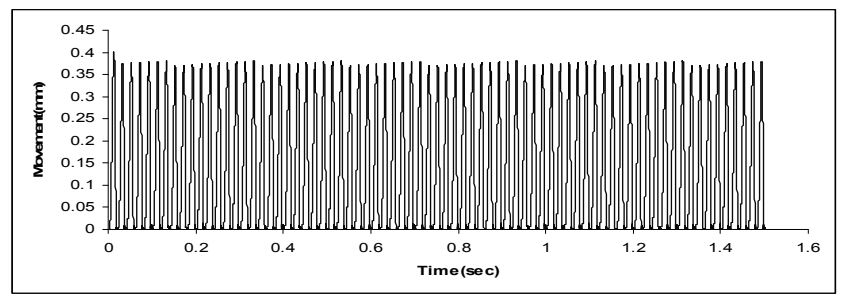

Fig. 4. Movement pattern for Power frequency for $75 \mathrm{kV} / \mathrm{Al} / 0.2$ $\mathrm{mm} / 12 \mathrm{~mm} / 100 \mu \mathrm{m}$ thickness coated enclosure.

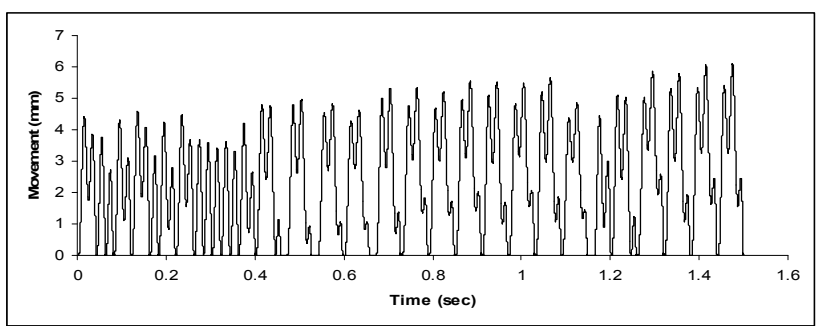

Fig. 5. Movement pattern for Power frequency for $75 \mathrm{kV} / \mathrm{Cu} / 12 \mathrm{~mm} / 0.2 \mathrm{~mm}$ radius uncoated enclosure.

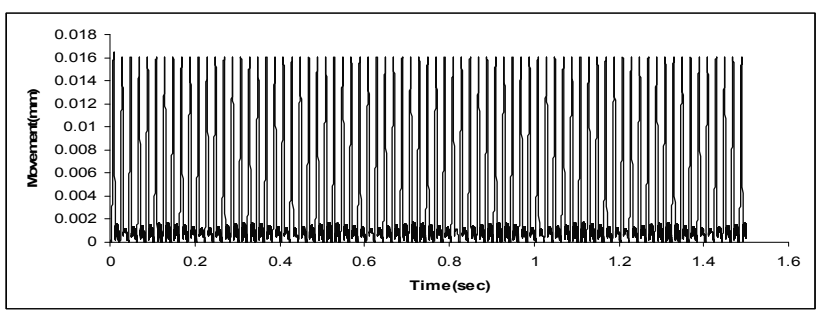

Fig. 6. Movement pattern for Power frequency for $75 \mathrm{kV} / \mathrm{Cu}$ $0.2 \mathrm{~mm} / 12 \mathrm{~mm} / 100 \mu \mathrm{m}$ thickness coated enclosure

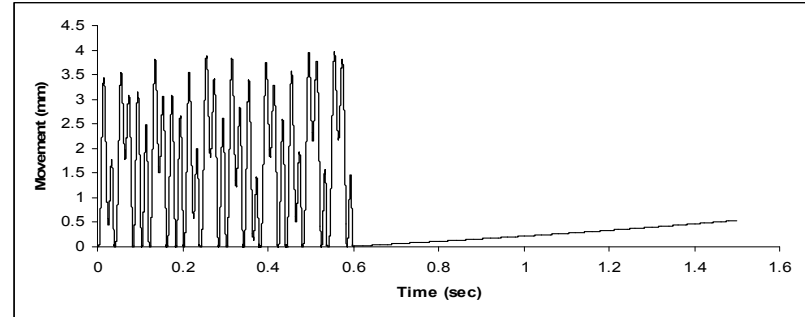

Fig. 7. Movement pattern for Power frequency for $75 \mathrm{kV} / \mathrm{Ag} / 12 \mathrm{~mm} / 0.2 \mathrm{~mm}$ radius uncoated enclosure.

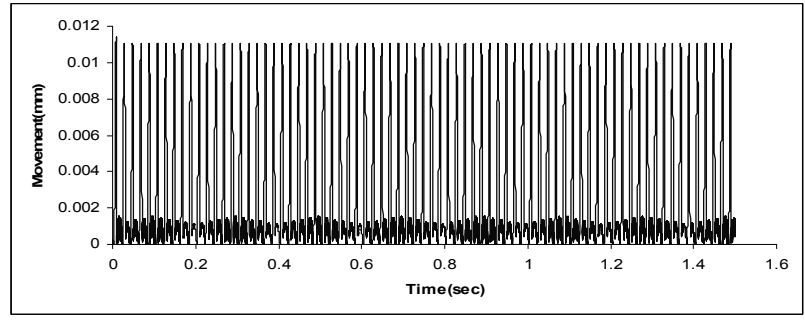

Fig. 8. Movement pattern for Power frequency for $75 \mathrm{kV} / \mathrm{Ag} / 0.2$ $\mathrm{mm} / 12 \mathrm{~mm} / 100 \mu \mathrm{m}$ thickness coated enclosure.

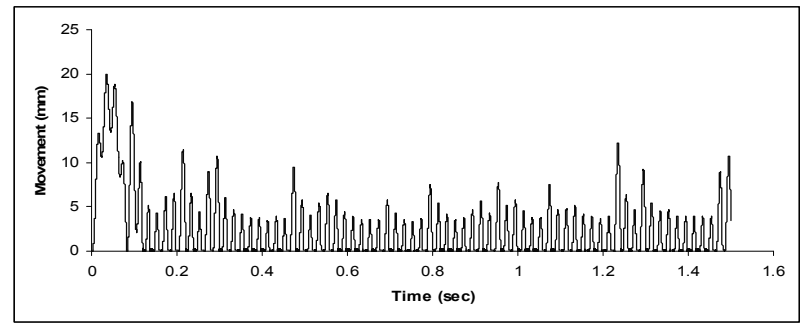

Fig. 9. Movement pattern for Power frequency for $145 \mathrm{kV} / \mathrm{Cu} / 12 \mathrm{~mm} / 0.2 \mathrm{~mm}$ radius uncoated enclosure.

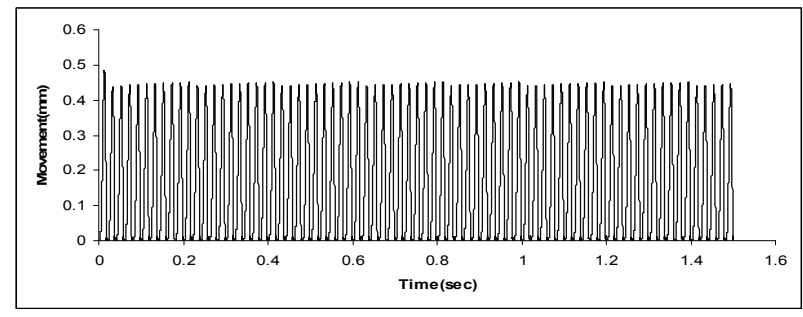

Fig. 10. Movement pattern for Power frequency for $145 \mathrm{kV} / \mathrm{Cu} / 0.2$ $\mathrm{mm} / 12 \mathrm{~mm} / 100 \mu \mathrm{m}$ thickness coated enclosure.

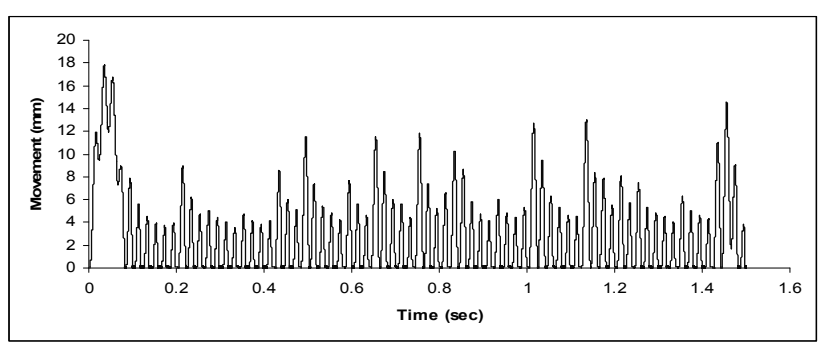

Fig. 11. Movement pattern for Power frequency for $145 \mathrm{kV} / \mathrm{Ag} /$ $12 \mathrm{~mm} / 0.2 \mathrm{~mm}$ radius uncoated enclosure

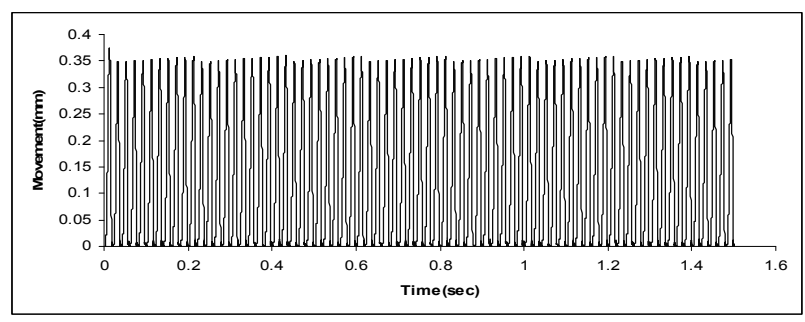

Fig. 12. Movement pattern for Power frequency for $145 \mathrm{kV} / \mathrm{Ag} / 0.2$ $\mathrm{mm} / 12 \mathrm{~mm} / 100 \mu \mathrm{m}$ thickness coated enclosure. 


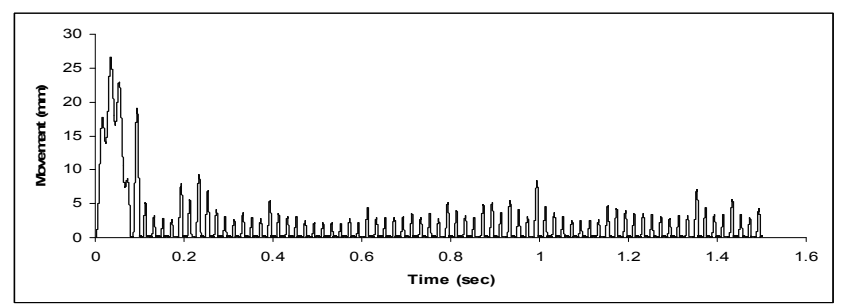

Fig. 13. Movement pattern for Power frequency for $200 \mathrm{kV} / \mathrm{Ag} /$ $12 \mathrm{~mm} / 0.2 \mathrm{~mm}$ radius uncoated enclosure

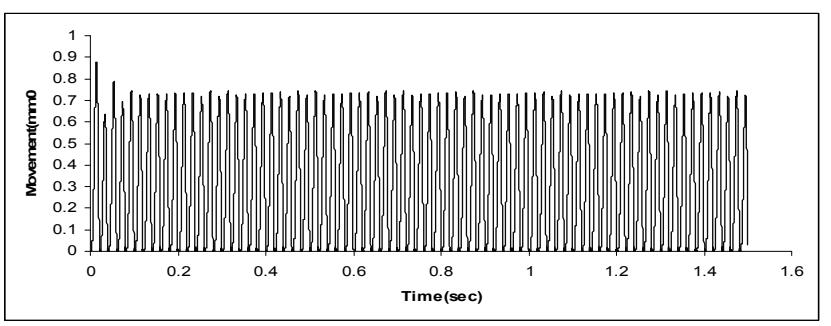

Fig. 14. Movement pattern for Power frequency for $200 \mathrm{kV} / \mathrm{Ag} /$ $0.2 \mathrm{~mm} / 12 \mathrm{~mm} / 100 \mu \mathrm{m}$ thickness coated enclosure.

\section{CONCLUSION}

A mathematical model has been formulated to simulate the particle trajectories in a Gas insulated Busduct. The movement patterns of Aluminum, Copper and Silver particles under different voltage conditions with and without dielectric coating in the presence of Electromagnetic field effect on the particle have been observed for a single phase isolated conductor GIS on bare electrode system. The results obtained are presented and analyzed. It has been observed that there is a considerably increase in movement of the particle when electromagnetic field effect on the particle is considered It has also been observed that the particle movement is greatly reduced while considering dielectric coating inside the surface of the enclosure. All the above investigations are carried out for various voltages under power frequency.

\section{ACKNOWLEDGMENT}

The authors are thankful to the management of Aditya Institute of Technology and Management, Tekkali, Srikakulam (Dist), and JNT University, Hyderabad, for providing facilities and to publish this work.

\section{REFERENCES}

[1] K. S. Prakash, K. D. Srivastava, and M. M. Morcos, "Movement of particles in compressed $\mathrm{SF}_{6}$ GIS with dielectric coated enclosure," IEEE Transactions on Dielectrics and Electrical Insulation, vol.4, no.3, pp.344-347, June1997.

[2] K. D. Srivastava and R.G. Van Heeswi jk, "Dielectric coatings Effect of break down and particle movement in GITL systems," IEEE transactions on Power Apparatus and Systems, vol. PAS- 104, no.1, pp. 22-31, January 1985.
[3] J. R. Laghari and A.H.Qureshi, "A Review of particle contaminated gas breakdown," IEEE Transactions on Electrical Insulation, vol. EI-16, no.5, pp. 388-398, October 1981.

[4] H. Anis and K. D. Srivastava, "Free conducting particles in compressed gas insulation," IEEE Tranctions on electrical insulation, vol. EI-16, pp.327-338, August 1995.

[5] M. M. Morcos, S. Zhang, K. D. Srivastava, and S. M. Gubanski, "Dynamics of metallic particle contamination in GIS with dielectric coating electrodes," IEEE Trans. Power Delivery, vol.15, pp. 455-460, 2000 .

[6] G. V. Nagesh Kumar, J. Amaranath, B. P. Singh, and K. D. Srivastava, "Electric field effect on metallic particle contamination in a common enclosure gas insulated busduct," IEEE Transactions on Dielectrics and Electrical Insulation, vol.14, no.2, pp.334- 340, April 2007.

[7] H. Anis and K. D. Srivastava, "Breakdown characteristics of dielectric coated electrodes in sulphur hexafluoride gas with particle contamination," sixth Intern, Sympos high Voltage engineering, paper no.32.06, New Orleans, LA, USA. 1989.

[8] J. R. Laghari and A. H. Qureshi, "A Review of particle contaminated gas breakdown," IEEE Transactions on Electrical Insulation, vol. EI-16, no.5, pp. 388-398, October 1981.

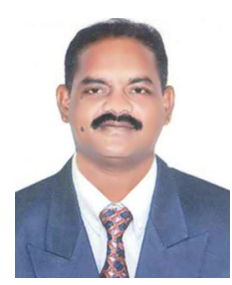

K. B. Madhusahu received the B. E. Degree in Electrical Engineering from College of Engineering, Gandhi Institute of Technology and Management, Visakhapatnam, India in 1985, and the M. E Degree in power Systems from College of Engineering, Andhra University, and Visakhapatnam in 1988. He obtained his Ph.D from Jawaharlal Nehru Technological University, Hyderabad. Currently he is working as a professor and Principal in the Department of Electrical and Electronics Engineering, A. I. T. A. M, Tekkali, and Srikakulam Dt. Andhra Pradesh. His research interests include gas insulated substations, high voltage engineering and power systems. He has published more than 22 research papers in national, international conferences and journals.

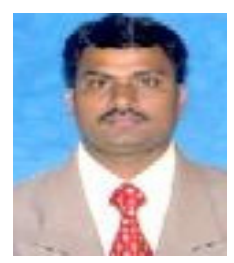

B. Srinivasa Rao obtained the B. Tech. Degree in EEE from RVR and JC College of Engineering, Guntur, 1999, M. Tech Degree in power Electronics from College of Engineering, JNTU, Hyderabad in 2008. He has more than 13 Years of Teaching Experience. Currently he is working as an Assoc. Professor in the Department of Electrical \& Electronics Engineering, Aditya Institute of Technology And Management, Tekkali, Srikakulam Dt. Andhra Pradesh. His research interests are power electronics and applications, power semiconductor drives.

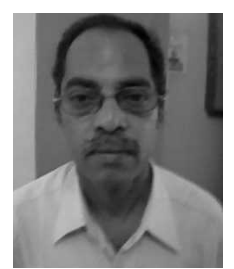

J. Amarnath obtained the B.E. degree in electrical engineering from OU, Hyderabad, A.P.India.in 1982 and the M.E. Degree In power systems from AU, Visakhapatnam in 1984. Presently he is professor in the department of Electrical Engineering, JNTU, Hyderabad, A.P., He presented more than 90 research papers in national and international conferences and journals. More than $12 \mathrm{Ph}$.Ds were awarded under his guidance. His research interests includes high voltage engineering, gas insulated substations, industrial drives, power electronics, power systems, microprocessors and microcontroller applications to power systems and industrial drives. 